\title{
The Relationship of STEM Attitudes and Career Interest
}

\author{
Eric Wiebe ${ }^{1 *}$, Alana Unfried ${ }^{2}$, Malinda Faber ${ }^{3}$ \\ ${ }^{1}$ Department of STEM Education, NC State University, Raleigh, NC, USA \\ ${ }^{2}$ Department of Mathematics and Statistics, California State University, Monterey Bay, CA, USA \\ ${ }^{3}$ Friday Institute for Educational Innovation, NC State University, Raleigh, NC, USA
}

Received 12 December 2017 - Revised 15 March 2018 - Accepted 24 May 2018

\begin{abstract}
This study examines the relationships between attitudes toward all core STEM subjects and interest in STEM careers among 4th through 12th grade US students through the administration of the Student Attitudes toward STEM (S-STEM) Survey to over 15,000 public school students. The research developed a model based on expectancy-value theory that incorporates key demographic factors of age, gender, and race/ethnicity. Our findings reinforce prior research that students across key demographic factors perceive biological/clinical and physical science career paths differently, resulting in two career clusters. Of interest, the relationship of mathematics attitudes to career interest varied by STEM career cluster. Findings were also supportive of the conclusion that students' attitudes towards STEM careers are not static over their primary and secondary grades, stabilizing and leveling during their secondary years. Gender showed significantly different interest levels for the two career clusters: males higher for physical sciences and females higher for biological/clinical sciences. Racial/ethnic disparity in STEM career interests can be seen more readily in physical sciences and engineering than in the biological sciences. Overall, our work reinforces findings that students, as young as elementary grades, are forming attitudinal associations between their academic and life experience and future STEM careers.
\end{abstract}

Keywords: attitudes, career interest, K-12, outcome expectancy, self-efficacy, STEM

\section{INTRODUCTION}

Preparing the next generation of leaders and workers with science, technology, engineering, and mathematics (STEM) skills, who can apply the rules of reason, the findings of science, the aesthetics of art, and sparks of creativity to improve society, is a national concern (NAE, 2014; NRC, 2010; PCAST, 2012). Current efforts by both private companies and public agencies to improve society have been increasing the demand for workers with these STEM skills and competencies (Rothwell, 2013). Yet participation in the STEM workforce among females and individuals from racial/ethnic minority backgrounds, particularly African Americans and Latinos, has been declining (cf., Miller, 2014; Xie \& Achen, 2009).

Much of the research efforts to understand a person's pathway into a STEM career has focused on the postsecondary timeframe, with less scrutiny paid to an individual's experiences during high school or earlier (e.g., Chen, 2009; Correl, 2001; Dewitt et al., 2011). Some researchers, however, have begun to investigate younger students' participation in these pathways. For example, Tai and colleagues (2006) found that a young student's aspirations in science were a better predictor of their enrollment in post-secondary science studies than their achievement during traditional schooling. Other research has highlighted the link between a person's early expectations and their eventual education and career choices in science (e.g., Beal \& Crockett, 2010; Dewitt et al., 2011; Eccles, Vida, \& Barber, 2004). Little research has been done that investigates all core STEM subjects; typically studies focus on students' interests and expectations regarding mathematics or science alone. To address this gap, our study examines the relationships between attitudes toward all core STEM subjects (science, technology,

(c) 2018 by the authors; licensee Modestum Ltd., UK. This article is an open access article distributed under the terms and conditions of the Creative Commons Attribution License (http://creativecommons.org/licenses/by/4.0/). $\square$ eric_wiebe@ncsu.edu (*Correspondence) $\square$ aunfried@csumb.edu $\square$ mmfaber@ncsu.edu 


\section{Contribution of this paper to the literature}

- This study surveyed over 15,000 public school students in the United States using the validated instrument, the Student Attitudes toward STEM (S-STEM) Survey.

- Our findings reinforce prior research that students across key demographic factors perceive biological/clinical and physical science career paths differently, resulting in two career clusters. Also found was an interesting relationship of mathematics attitudes to career interest that varied by STEM career cluster.

- Findings indicated that students' attitudes towards STEM careers are not static over their primary and secondary school years. In addition, gender showed significantly different interest levels for the two career clusters.

engineering, and math) and interest in STEM careers among 4th through 12th grade students, with special attention paid to the role of students' gender and racial/ethnic backgrounds.

\section{LITERATURE REVIEW}

\section{Defining Attitudes}

For this research, students' attitudes towards STEM careers are guided by expectancy-value theory (Eccles \& Wigfield, 2002; Wigfield \& Eccles, 2000), which takes the fundamental notions of self-determination theory (Deci \& Ryan, 1985) and sets them within a goal-directed environment, such as academic and career trajectories. Expectancy-value theory helps frame both self-efficacy in terms of expectancies of success in a particular academic domain and outcome expectancy in terms of the value of this academic subject area to future goals. Numerous researchers have found links between domain-specific self-efficacy and academic outcomes (e.g., Pajares \& Graham, 1999; Schunk, 1991; Simon, Aulls, Dedic, Hubbard, \& Hall, 2014). Similarly, outcome expectancies for success and the value a student associates with it have been found to directly influence performance, persistence, and choice in (academic) tasks (Eccles \& Wigfield, 2002; Guo, Marsh, Morin, Parker, \& Kaur, 2015). Earlier in the development of these social psychology theories, researchers explored the influence of demographics-including age, gender, and race/ethnicity - on development of self-efficacy, outcome expectations and career interest (cf., Fouad \& Smith, 1996). For example, for older individuals closer to career entry (post-college for most STEM careers), personal goals may be aligned with actual career choices, while earlier in a student's academic life, they may be manifested in broader, more abstracted career interests. There is a dynamic, reciprocal nature of self-efficacy, expectancy outcomes and academic-career goals that emerge from these psychological states and evolve over time.

\section{Experiences, Attitudes and Career Interest}

A number of researchers have explored the reciprocal relationship between experiences in STEM academic subjects and the development of domain-specific career interests. Research has shown that students are more likely to pursue postsecondary schooling in STEM fields if they have success in mathematics (Wang, 2012) or high selfefficacy in science (Scott \& Mallinckrodt, 2005) in earlier grades. Similarly, during high school, having high expectancy-value beliefs has been found to be associated with a student's persistence in taking both advanced science and mathematics courses (Simpkins, Davis-Kean, \& Eccles, 2006). There is a reciprocal relationship over time that likely helps correct for mis-calibration of self-efficacy relative to the academic task performance (Chen \& Zimmerman, 2007). This suggests that although some adolescents maintain their aspirations and expectations for the future, for others, future-oriented cognitions are in flux (Beal \& Crockett, 2010).

Researchers have found high-school-age students able to provide meaningful information about their interests in future STEM careers (e.g., Jenkins \& Nelson, 2005). These interests seem to be somewhat stable at this age, as Sadler, Sonnert, Hazari, and Tai (2012) found that students' career interests when entering high school were the strongest predictors of their career interests when leaving high school. Researchers looking across longer grade spans have shown mixed results concerning the stability of attitudes and their relationship to career interests. DeWitt, Archer, and Osborne (2014) found that interest in a science career often diminished with age such that by the time students were 14 or 15, many students saw it as unthinkable they would become a scientist. Mau (2003) concurred, finding fewer than one-quarter of eighth graders retained an interest in pursuing a science or engineering career six years later. For those students interested in a science degree, Maltese and Tai (2011) found that eighth-grade students who believed science would be useful for their future and who were interested in a science career were more likely to earn degrees in STEM. While students in younger grades may not have detailed understandings of all possible STEM career pathways, they are beginning to differentiate them in broader ways (Maltese \& Tai, 2011). Tai and colleages (2006) found that interest in a science career in eighth grade showed 
differing predictive likelihoods of a STEM major depending on whether it was a life science or physical science degree. This study also found that eighth grade mathematics achievement was more predictive of a physical science degree path than biological sciences.

In summary, this literature paints a compelling picture that student STEM attitudes and career interests are in flux during their elementary and secondary school years, though stabilizing and solidifying some during their secondary years. This research has typically been conducted on a single academic area of STEM (e.g., science or mathematics), however, with career interest mappings that are similarly restricted. This work is not exploring potentially important interactions between STEM areas, such as mathematics and science attitudes and future engineering career interest, or how students tend to categorize or group various STEM careers. Further, these complex relationships should be explored across a broad range of ages.

\section{Gender}

Eccles has used expectancy-value theory to specifically study women in STEM career pathways (Eccles, 1994; Eccles \& Wigfield, 2002). She concluded that while significant differences based on gender are seen in participation in many STEM areas, the underlying reasons are complex and nuanced. In other research guided by expectancyvalue theory, Watt and colleagues (2012) found gender-based differences in perceived value, subsequent mathematics course selection, and career aspirations. Similarly, researchers have concluded that there is considerable evidence indicating boys and girls have differing attitudes towards, or engagement with, school science (c.f., Miller, Slawinski Blessing, \& Schwartz, 2006; Osborne, Simon, \& Collins, 2003).

Because of the breadth of sub-disciplines in science, researchers have examined science sub-discipline interactions with gender as well. Simon and colleagues (2014) documented these gender-based differences in selfefficacy in STEM subject areas, helping to explain differences seen in male-dominated academic areas such as physics (Yerdelen-Damar \& Pesman, 2013). Work by Hazari and colleagues (2010) point to the role of future value as possible cause for lower career interest in physics for girls, paralleling findings regarding gender differences in the task value for mathematics (Watt et al., 2012). These findings are supported by PISA (OECD, 2006) data analysis showing that girls are more interested in living systems (Miller et al., 2006), while boys are more interested in physical sciences (Drechsel, Carstensen, \& Prenzel, 2011 ). This declining interest by girls in engineering, computer science and mathematics often parallels rising interest in health and medical professions (Sadler et al., 2012).

Age has emerged as a factor that has important interactions with gender. Researchers have documented how social influences regarding science career paths begin to exert their effect in elementary grades and are differentiated by gender (Greenfield, 1997). In a literature review of girls' engagement in science, Brotman and Moore (2008) cite multiple studies documenting either less positive attitudes towards science by girls and/or sharper declines over time (cf., Mau, 2003). A more recent cross-sectional study (Unfried, Faber, \& Wiebe, 2014) has documented a divergence in self-efficacy and outcome expectancy between boys and girls in physical sciences and engineering starting in elementary grades.

\section{Race/Ethnicity}

It is well documented that African-Americans and Hispanics are historically under-represented in STEM fields relative to the population as a whole (NSF, 2009; Washington, 2011). In contrast, Asians and Caucasians are, in general, over-represented in the U.S. in STEM professions (Beede et al., 2011). A more open question is the underlying causes for these racial and ethnic disparities. In DeWitt's (DeWitt et al., 2011) U.K. study, the researchers reached the conclusion that external factors such as parental influence were the primary underlying cause for similar demographic disparities. Among a racially diverse population of high achieving mathematics students, Caucasian students showed stronger motivation for science persistence over African-American students and Hispanic students (Andersen \& Ward, 2013). In a contrasting study, Riegle-Crumb and King (2010) found that once K-12 academic preparation is taken into account, African-Americans are more likely to declare and persist in STEM majors. Just as with gender, race and ethnicity disparity is present within the science fields. Caucasians are overrepresented in engineering and physical science majors, while biological sciences draws its majors more equitably from all racial groups (Riegle-Crumb \& King, 2010).

In summary, important research findings have emerged with regard to gender differences in academic attitudes and the types of careers boys and girls are interested in. Equally important work has found that differences in academic attitudes may not be the root cause of differing STEM career participation across racial and ethnic groups. Research on differences among underrepresented populations has typically been constricted to one demographic dimension (e.g., gender) within one STEM content area, making it difficult to look at gender and racial/ethnic differences holistically across all the STEM areas. 


\section{Twenty-First Century Skills}

Authentic STEM practices used in STEM-related careers, such as integrated, inquiry-based, and hands-on activities, have seen increased emphasis in K-12 classrooms. Many early advocates of these 21st century skills (PTCS, 2005) were from the business sector (e.g., Cisco Systems, 2008), but these policy recommendations have increasingly been channeled through federal government policy initiatives (e.g., Katehi, Pearson, \& Feder, 2009; PCAST, 2010). This movement built a foundation for the Next Generation Science Standards (NGSS Lead States, 2013) that formally emphasized these science and engineering practices in K-12 science education. At the same time, the nascent K-12 engineering education movement has spurred research on engineering's influence on core content instruction (Nathan, Oliver, Prevost, Tran, \& Phelps, 2009) and the implications for teacher professional development (Douglas, Rynearson, Yoon, \& Diefes-Dux, 2015). What has been less studied is how this engineering and STEM education movement in the K-12 instructional space has influenced students' attitudes about these STEM and engineering practices, core STEM academic subjects, and their interest in future STEM careers that use this skill set. Our study examines this relationship.

\section{STEM Career Taxonomies}

Research linking STEM attitudes to career pathways has been made more difficult by the lack of consensus over what the STEM career taxonomy should be. Almost all U.S. government published taxonomies of STEM careers tend to include mathematics, natural and physical sciences, computer science, engineering, and technologist positions. There is more debate regarding whether or not to include social sciences and medical and health sciences among STEM careers. For example, the National Science Foundation includes social sciences, but excludes medical and health sciences (NCSES, 2013). The U.S. Department of Education aligns their definition of STEM careers with recent legislative efforts that exclude both social and medical sciences (Chen, 2009; Ginder \& Mason, 2011). Furthermore, institutions that interface closely with K-12 education, such as ACT, have chosen to include medical and health sciences but exclude social sciences (ACT, 2009). This approach perhaps reflects a more pragmatic approach of connecting students' day-to-day experiences with academics and popular culture. ACT also combines Engineering and Technology, reflecting current standards documents such as the Next Generation Science Standards (ACT, 2014; NGSS Lead States, 2013). In this paper, our approach in defining STEM is similar to that of ACT. We include medical and health sciences, but exclude social sciences.

\section{Purpose of this Study}

Demographic factors such as age (Mau, 2003), gender (Sadler et al., 2012), and race/ethnicity (Riegle-Crumb \& King, 2010) have been established as important variables in STEM career pathways research that use expectancyvalue theory. Differences among demographic groups have been found not only across core academic areas such as mathematics and science, but also within sub-disciplines in science (Drechsel et al., 2011). Research to date points to divides between biological and physical sciences (cf., Tai et al., 2006) and their relationship to medical/health career pathways (cf., Sadler et al., 2012). Findings such as these highlight the importance of utilizing a broad taxonomy of STEM career pathways, such as the one ACT (2009) has defined. Further exploration is also needed regarding how students perceive the relationships between various STEM career paths - do they think of various STEM career pathways similarly or differently? Also, research looking at the relationship of STEM academic areas to career pathways needs to include the '21st century skills' (PTCS, 2005) that have been operationalized through explicit academic instruction in engineering and other areas of K-12 STEM education (NAE, 2014; NGSS Lead States, 2013).

The following research looks to address some of the important questions in STEM career pathways research by examining a large-scale, cross-sectional sample of students who have been exposed to new academic trends in integrative STEM education. In addition, this work will be done by looking holistically across all STEM academic areas and a broad range of career pathways. The research will develop a model that incorporates key demographic factors of age, gender, and race/ethnicity. In doing this work, the following two questions will be asked:

1. How do STEM career paths cluster based on student interest?

Answering this first question sets the stage for looking at the relationship of these clusters and STEM academic areas:

2. What is the relationship between attitudes (self-efficacy and outcome expectancy) in STEM academic areas and STEM career interests?

For this second question, the following sub-questions will be addressed:

- What is the relationship between STEM academic attitudes and STEM career interest?

- How do attitudes towards 21st century skills relate to STEM career interest? 
Table 1. Sample Items from the Four Attitudinal Constructs

\begin{tabular}{ll}
\hline Construct & Sample Items \\
\hline \multirow{2}{*}{ Mathemce } & I am sure of myself when I do science. \\
\hline \multirow{2}{*}{ Engineering and Technology } & $\frac{\text { I lim the type of student to do well in math. }}{\text { I } \text { I believe I can be successful in a career in engineering. }}$ \\
\hline \multirow{2}{*}{ 21st Century Skills } & I am confident I can lead others to accomplish a goal. \\
\hline
\end{tabular}

- How do demographic variables of age, gender, and race/ethnicity relate to STEM career interest?

- Do these predictors differ based on career cluster?

\section{METHODS}

To explore the relationships between primary and secondary students' self-efficacy and outcome expectancy for science, technology, engineering, and mathematics attitudes, and their interest in STEM career fields, our study examined a large sample of students in schools in their first and second years implementing STEM education programs. With important policy questions being asked regarding implementation and efficacy of STEM educational programs, this sampling strategy allowed us to explore these baseline attitudes and interests of students at the front edge of long-term STEM program implementations.

\section{Survey Instrument}

To better understand the relationships between students' STEM self-efficacy and expectancy values and career interests, as well as the relationships between these attitudes and interests and other demographic, attitudinal, and experiential factors, we developed and administered the Student Attitudes toward STEM (S-STEM) Survey to over 15,000 public school students in the state of North Carolina, USA. The S-STEM Survey has a middle and high school version appropriate for 6th through 12th grade students and an upper elementary version for 4th and 5th grade students. Psychometric tests, including exploratory and confirmatory factor analysis, showed that the attitudes constructs and career interest items were valid and reliable (Cronbach's Alpha ranged from .83 to .92), and tests for measurement invariance demonstrated that the survey measures the same information in the same ways across students of different ages, races/ethnicities, and genders. More recently, the instrument has been translated to Turkish and revalidated for use in STEM attitudinal research in that country (Yerdelen, Kahraman, \& Tas, 2016; Yildirim \& Selvi, 2015). More detailed information about the development and validation of the S-STEM Survey can be found in Unfried, Faber, Stanhope, and Wiebe (2015); the sample used in this article was also used for the confirmatory factor analysis and measurement invariance testing for instrument validation.

\section{Attitudes constructs}

In the S-STEM Survey three constructs measure student attitudes toward all four primary STEM subjects: science (9 items), mathematics (8 items), and engineering/technology (9 items). Each item uses a five-point Likert scale from strongly disagree to strongly agree and asks students to agree or disagree with both self-efficacy items, such as 'I am sure I could do advanced work in math,' and expectancy value items, such as 'I will need a good understanding of math for my future work.' Sample items can be seen in Table 1. Based on our literature review, at the recommendation of subject matter experts, and with supporting evidence from related psychometric tests (e.g., NAEP, 2014), we intentionally combined items measuring engineering and technology attitudes into one construct. This reasoning was driven in part by the conflation of engineering and technology as both an academic field of study and career path by policy makers and the public press. While technology and engineering are understood as separate career paths for professionals in these areas, this distinction is likely lost on K-12 students. For example, in the US, K-12 engineering education is often taught by technology education teachers (cf., ITEEA, 2018). A fourth construct measures students' attitudes toward 21st century skills, using the same five-point Likert response scale (see Table 1).

\section{Career interest section}

The S-STEM Survey measures student interest in twelve STEM career pathways: physics, environmental work, biology and zoology, veterinary work, mathematics, medicine, earth science, computer science, medical science, 
chemistry, energy, and engineering. These pathways were developed from a set of 43 pilot items that were based on the U.S. Bureau of Labor Statistics (2011) Occupational Outlook Handbook, and then refined using exploratory factor analysis. The career interest section uses a four-point Likert scale from not at all interested to very interested. We were careful to include titles of occupations that require four-year and graduate degrees, as well as titles of occupations that require two-year degrees or similar levels of training and preparation. One item reads, for example, 'Computer Science: consists of the development and testing of computer systems, designing new programs and helping others to use computers. (computer support specialist, computer programmer, computer and network technician, gaming designer, computer software engineer, information technology specialist).'

\section{Academic or external items}

To partially account for external factors that may affect student interest in STEM, the survey includes four items asking students whether or not they know adults working in STEM fields. To account for students' more immediate expectations for their academic performance in science and mathematics, the survey asks students how well they expect to do in their science and mathematics classes in the coming semester (Not Very Well, OK/Pretty Well, or Very Well). This variable also serves as a proxy for student academic performance, since we were not able to collect data on students' grades or other academic achievements. Because literacy is recognized as central to success in STEM academic areas (Yore, Bisanz, \& Hand, 2003), we also measured their near-term academic performance expectations for their English class.

\section{Demographic items}

Given the preponderance of research findings suggesting that age, race/ethnicity, and gender play important roles in student attitudes toward STEM subjects and interest in STEM careers over time, we included these demographic items in the S-STEM Survey. In this study we used the student's grade-level as a proxy for their age.

\section{Sample}

The S-STEM Survey was administered to 15,155 fourth through twelfth grade students in North Carolina public schools that were in their first and second years implementing STEM-focused education initiatives. Of those students 11,850 were in 118 schools across multiple school districts implementing STEM programs that were funded by a state-based foundation, and 3,305 students were in 13 schools implementing a 'STEM school' program led by a single district. The students completed the S-STEM survey online during the 2012-13 school year. This survey was administered anonymously, with only grade and school information collected. There is an approximate response rate of $69.1 \%$ for the first grant initiative and $66.2 \%$ for the second initiative.

Approximately $1 \%$ of the surveys had no variation in responses across all items, indicating student disinterest, and were removed from the dataset. Of the 15,009 survey responses remaining after cleaning, $90.7 \%$ of responses had no missing data. Missing data percentages for each survey item ranged from $0.0 \%$ to $5.9 \%$, with a mean of $2.67 \%$ and standard deviation of $1.9 \%$. Missing values were imputed using the EM algorithm in SAS/STAT® software, Version 9.4 (Truxillo, 2005).

Survey respondents were 1) 50.8\% male and 49.2\% female, and 2) 55.8\% Caucasian, 16.5\% African American, 12.8\% Hispanic/Latino, 4.7\% Multiracial, 4.6\% Other, 3.1\% American Indian/Alaskan Native, and 2.4\% Asian/Pacific Islander. This demographic distribution deviates somewhat from the current North Carolina state (64.0\% Caucasian, 21.5\% African American, 8.9\% Hispanic/Latino; USCB, 2016) and U.S. national distributions (62.0\% Caucasian, 12.6\% African American, 17.3\% Hispanic/Latino; USCB, 2016). In addition, our sample contains higher proportions of 5th through 8th grade students than is found statewide in North Carolina (NCDPI, 2009). The grade distribution can be seen in Table 2 . 
Table 2. Distribution of Grade for Survey Respondents

\begin{tabular}{ccc}
\hline Grade & Frequency & \% \\
\hline 4 & 1442 & 9.6 \\
\hline 5 & 3074 & 20.5 \\
\hline 6 & 1738 & 11.6 \\
\hline 7 & 2475 & 16.5 \\
\hline 8 & 3912 & 26.1 \\
\hline 9 & 559 & 3.7 \\
\hline 10 & 316 & 2.1 \\
\hline 11 & 1303 & 8.7 \\
\hline 12 & 190 & 1.3 \\
\hline Total & 15009 & 100 \\
\hline
\end{tabular}

\section{Cluster Analysis}

The first objective in this study was to examine how career paths cluster based on student interest. In particular, we were interested in whether the clusters we found would follow previously seen bifurcations of biological versus physical sciences (e.g., Miller, et al., 2006; Sadler, et al., 2012), and where clinical professions such as medical and veterinary science fall in comparison to other traditional STEM fields. To answer these questions, cluster analysis was used to group the 12 S-STEM career interest survey items. Since the career items are ordinal variables, clustering of variables was completed on the Spearman correlation matrix using hierarchical oblique principal component cluster analysis in SAS/STAT® software, Version 9.4 (SAS Institute Inc., 2014). The clusters were created hierarchically, starting with one cluster, until each cluster had only a single eigenvalue greater than one. Once the career clusters were found, student scores for each item within a cluster were averaged together to create a career cluster score for each student on each career cluster.

\section{Multiple Linear Regression}

The second objective of this study was to examine the relationship between attitudes in STEM academic areas and STEM career interests. This relationship can be assessed using multiple linear regression analysis with a career cluster score as the dependent variable. We employ variable selection techniques to identify the variables that are the strongest predictors of career cluster scores.

\section{Dependent variables}

For each career cluster found, a separate regression analysis was run using the career cluster score described previously. This allowed for comparisons in predictors resulting from the variable selection process. We chose to use a career cluster score rather than predicting 12 individual career interests. Working with pre-college students, we concluded it was better to look broadly at the relationship of attitudes to career interests, since students' comprehension of specific occupations grows over time (Watson \& McMahon, 2005) and is unlikely to have matured in the younger grades. Also, students do not necessarily study specific STEM careers in school, but rather study STEM academic subject areas, which may better map to STEM career clusters than individual professions.

\section{Independent variables}

Theoretic, statistical, and pragmatic considerations guided how variables were combined or simplified to reduce the number of variables under consideration in the models. First, a mean construct score was calculated for each student on each of the four attitudes factors. These scores range from 1 to 5 . Race/ethnicity was redefined as a dichotomous variable representing overrepresented and underrepresented students. Based on current demographic analyses (e.g., Beede et al., 2011), Caucasian and Asian students were categorized as overrepresented in STEM, and all other races/ethnicities were categorized as underrepresented in STEM. Four items asking students if they know any adults who work as a scientist, mathematician, engineer, or technologist, were combined into one variable. This new ordinal variable, STEM Adults, is a measure, on a scale of 0 to 4 , of breadth of exposure a student has to adults working in STEM fields. With these simplified variables, plus grade, gender, and three academic outcome expectancy items, 11 variables from the survey were considered as independent variables for predicting STEM career clusters. Lastly, an 'Initiative' variable was included to account for any affect that sampling from two different grant initiatives may have. This gives a total of 12 main effects considered for the regression model, all of which are listed in Table 3. 
Table 3. List of main effects considered in each multiple linear regression model

\begin{tabular}{l}
\hline Variable Name \\
\hline Science Attitudes \\
\hline Mathematics Attitudes \\
\hline Engineering/Technology Attitudes ${ }^{c}$ \\
\hline 21st Century Skills Attitudes ${ }^{c}$ \\
\hline Race/Ethnicity $^{\text {STEM Adults }}$ \\
\hline Grade $^{c}$ \\
\hline $\begin{array}{l}\text { Gender } \\
\text { Initiative }\end{array}$ \\
\hline Science Academic Outcome Expectancyc \\
\hline Mathematics Outcome Expectancyc \\
\hline English/Language Arts Academic Outcome Expectancy ${ }^{c}$ \\
\hline Note: 'c' indicates the variable is treated as continuous in the regression model.
\end{tabular}

Table 4. List of Career Interest Items Included in Each Cluster

\begin{tabular}{cc}
\hline CoreSTEM Cluster & Bio/Med Cluster \\
\hline Physics & Biology and Zoology \\
\hline Environmental Work & Veterinary Work \\
\hline Mathematics & Medicine \\
\hline Earth Science & Medical Science \\
\hline Computer Science & \\
\hline Chemistry & \\
\hline Energy & \\
\hline Engineering &
\end{tabular}

We also considered possible two-way interactions between these independent variables. This is especially important in order to test if the relationship between STEM attitudes and STEM career interests differs across key demographic groups. Lastly, we considered quadratic terms for each of the continuous independent variables to account for possible non-linear trends. All continuous independent variables that did not have a natural interpretation at zero were centered around their total means (attitudes construct scores, grade, and academic outcome expectancy items). Centering continuous variables prior to regression analysis can make parameter estimate interpretations more interpretable, and is also important when considering interaction or quadratic terms to reduce the effects of collinearity (Jaccard \& Turrisi, 2003).

\section{Stepwise variable selection}

Due to the large number of variables under consideration in the model, it was not feasible to include all possible variables in the model. Although expectancy value theory gives us the general form of a theoretical model that could be tested (attitudes, demographics and academic expectancies for predicting career interest), the basic framing of expectancy value theory does not give us enough specificity to determine which interaction or quadratic terms should be included in the model. Further, even if we were to prefer a theoretical model, our large sample sizes would lead to finding almost every term significant. Driven by our intent to identify the variables that are the strongest predictors of STEM career interest, as well as the need to reduce the number of terms for model interpretation, we employed stepwise variable selection methods to select a subset of independent variables. At each step, stepwise selection adds or removes the variable that gives the greatest improvement to the overall model fit. We followed the hierarchical principle, which states that we should not include interaction effects or quadratic terms without also including the related main effects (James, Witten, Hastie \& Tibshirani, 2013). The procedure ends when a stopping criterion is reached. We chose to avoid the use of $p$-values in selecting variables since our large sample size almost always resulted in significant $p$-values. Instead, we used the Bayesian Information Criterion (BIC; Schwarz, 1978) as our method for assessing model fit at each step, and initially used it as the final stopping criteria as well.

\section{RESULTS}

\section{Cluster Analysis}

The 12 S-STEM Career Interest items were analyzed using cluster analysis. The resulting structure showed two clusters explaining $49.2 \%$ of total variation in the data (Table 4 ). 
Table 5. Total Means for each Attitudes Construct and Career Cluster, Across Demographic Variables

\begin{tabular}{|c|c|c|c|c|c|c|c|}
\hline & & $\begin{array}{c}\text { CoreSTEM } \\
\text { Cluster }\end{array}$ & $\begin{array}{l}\text { Bio/Med } \\
\text { Cluster }\end{array}$ & $\begin{array}{c}\text { Mathematics } \\
\text { Attitudes }\end{array}$ & $\begin{array}{c}\text { Science } \\
\text { Attitudes }\end{array}$ & $\begin{array}{l}\text { Engineering/ } \\
\text { Technology } \\
\text { Attitudes }\end{array}$ & $\begin{array}{c}\text { 21st Century } \\
\text { Skills } \\
\text { Attitudes }\end{array}$ \\
\hline Total & & 2.30 & 2.47 & 3.53 & 3.44 & 3.45 & 4.00 \\
\hline \multirow{2}{*}{ Gender } & Male & 2.48 & 2.29 & 3.57 & 3.47 & 3.73 & 3.92 \\
\hline & Female & 2.13 & 2.65 & 3.48 & 3.41 & 3.16 & 4.09 \\
\hline \multirow{2}{*}{$\begin{array}{c}\text { Race/ } \\
\text { Ethnicity }\end{array}$} & Over-represented & 2.28 & 2.47 & 3.57 & 3.50 & 3.45 & 4.02 \\
\hline & Under-represented & 2.34 & 2.46 & 3.47 & 3.36 & 3.45 & 3.97 \\
\hline \multirow{9}{*}{ Grade } & 4 & 2.56 & 2.66 & 3.67 & 3.46 & 3.57 & 4.03 \\
\hline & 5 & 2.51 & 2.59 & 3.69 & 3.52 & 3.64 & 4.04 \\
\hline & 6 & 2.35 & 2.46 & 3.55 & 5.53 & 3.48 & 3.98 \\
\hline & 7 & 2.24 & 2.42 & 3.50 & 3.43 & 3.44 & 3.97 \\
\hline & 8 & 2.17 & 2.39 & 3.45 & 3.38 & 3.33 & 3.97 \\
\hline & 9 & 2.16 & 2.34 & 3.41 & 3.48 & 3.36 & 3.92 \\
\hline & 10 & 2.13 & 2.35 & 3.32 & 3.29 & 3.22 & 3.87 \\
\hline & 11 & 2.14 & 2.38 & 3.37 & 3.39 & 3.33 & 4.12 \\
\hline & 12 & 2.11 & 2.39 & 3.24 & 3.29 & 3.28 & 3.97 \\
\hline \multicolumn{2}{|c|}{ Standard Deviation Range } & $(0.61,0.70)$ & $(0.70,0.75)$ & $(0.81,1.03)$ & $(0.73,0.89)$ & $(0.77,0.88)$ & $(0.59,0.73)$ \\
\hline
\end{tabular}

Note: Means given are total means, prior to centering variables

Results from the cluster analysis suggest that students tend to think of STEM career areas in two groups. Students tend to associate physics, environmental work, mathematics, computer science, chemistry, energy, and engineering with each other. We have chosen to call this cluster 'CoreSTEM,' as it contains the majority of subject areas that are commonly considered a part of STEM. Alternatively, students tend to associate biology, zoology, veterinary work, medicine, and medical science with each other. We call this cluster 'Bio/Med' since it includes both biology and medical careers.

A CoreSTEM cluster score and a Bio/MEd cluster score were calculated for each student, as the mean of the items included in each respective cluster. Career cluster scores range from 1 to 4,1 indicating no interest in the cluster and 4 indicating high interest in the cluster.

\section{Descriptive Statistics}

Means for each career cluster and attitudes construct are shown in Table 5, in relation to the demographic variables gender, race/ethnicity, and grade. Further, the mean grade was 7, mean English academic outcome expectancy score was 2.38, mean Mathematics academic outcome expectancy score was 2.34, and the mean Science academic outcome expectancy score was 2.39 .

\section{Stepwise Selection}

Using the BIC as a stopping criteria resulted in 21 effects entered into the CoreSTEM model and 19 entered into the Bio/Med model, aside from the intercept. In both cases, this was too many variables to allow for interpreting a parsimonious solution. Further, the later additional variables only made marginal changes in the values of the BIC and the adjusted $\mathrm{R}^{2}$. Our interests lie with which effects are the strongest predictors of career interest. Therefore, we made the decision to stop selecting variables after 10 effects (plus the intercept) had been added to each of the models. For both the CoreSTEM and Bio/Med models, retaining the additional effects selected by the BIC would have only increased the adjusted $\mathrm{R}^{2}$ value by 0.01 . Unselected variables may be statistically significant, but for our purposes they are not practically significant.

Tables 6 and 7 show the order in which the 10 selected effects entered the CoreSTEM and Bio/Med models respectively. Similarities in the two models are that 1) engineering/technology and science attitudes are among the top three predictors in both models; 2) grade and gender are in the top five predictors in each model; and 3) 21st century skills attitudes appears in the top 10 for both models. Differences between the two models are that 1) while mathematics attitudes is in the top five for the CoreSTEM model, it is not in the top ten for Bio/Med, nor was it among the 19 variables selected based on BIC for Bio/Med; 2) race appears in the CoreSTEM model but not in the Bio/Med model; 3) STEM Adults is a top 10 predictor of CoreSTEM but not of Bio/Med. The Bio/Med model also has more interaction terms in the top ten than the CoreSTEM model. Also note that those items missing from the top ten items for both models include how students expect to do in their coursework that year and the 'Initiative' variable. 
Table 6. Stepwise Selection Results and Parameter Estimates for CoreSTEM Model

\begin{tabular}{clcccc}
\hline Step & Effect Entered & Adjusted $\mathbf{R}^{\mathbf{2}}$ & BIC & Estimate & SE \\
\hline 0 & Intercept & .000 & $-12,595$ & 2.21 & 0.010 \\
\hline 1 & Engineering/Technology Attitudes & .342 & $-18,873$ & 0.34 & 0.006 \\
\hline 2 & Science Attitudes & .383 & $-19,826$ & 0.19 & 0.006 \\
\hline 3 & Grade & .402 & $-20,275$ & -0.05 & 0.002 \\
\hline 4 & Mathematics Attitudes & .412 & $-20,538$ & 0.09 & 0.005 \\
\hline 5 & Gender (Male) & .421 & $-20,745$ & 0.11 & 0.009 \\
\hline 6 & Grade & .426 & $-20,868$ & 0.01 & 0.001 \\
\hline 7 & Race/Ethnicity (Overrepresented) & .430 & $-20,962$ & -0.08 & 0.008 \\
\hline 8 & Science Attitudes * Engineering/Technology Attitudes & .433 & $-21,032$ & 0.05 & 0.005 \\
\hline 9 & STEM Adults & .434 & $-21,071$ & 0.02 & 0.003 \\
\hline 10 & 21st Century Skills Attitudes & .437 & $-21,119$ & -0.06 & 0.007 \\
\hline
\end{tabular}

Note: Gender uses 'Female' as the reference level. Race/Ethnicity uses 'Underrepresented' as the reference level. All $p$-values are $<.0001$

Table 7. Stepwise Selection Results and Parameter Estimates for Bio/Med Model

\begin{tabular}{|c|c|c|c|c|c|}
\hline Step & Effect Entered & Adjusted $\mathbf{R}^{2}$ & BIC & Estimate & SE \\
\hline 0 & Intercept & .000 & $-9,199$ & 2.66 & 0.010 \\
\hline 1 & Science Attitudes & .138 & $-11,430$ & 0.29 & 0.007 \\
\hline 2 & Gender (Male) & .207 & $-12,666$ & -0.41 & 0.012 \\
\hline 3 & Engineering/Technology Attitudes & .218 & $-12,861$ & 0.07 & 0.008 \\
\hline 4 & Grade & .225 & $-12,991$ & -0.04 & 0.003 \\
\hline 5 & Grade $^{2}$ & .228 & $-13,047$ & 0.01 & 0.001 \\
\hline 6 & Grade * Science Attitudes & .232 & $-13,107$ & 0.04 & 0.003 \\
\hline 7 & Grade * Engineering/Technology Attitudes & .236 & $-13,169$ & -0.03 & 0.003 \\
\hline 8 & 21st Century Skills Attitudes & .238 & $-13,206$ & 0.08 & 0.009 \\
\hline 9 & Engineering/Technology Attitudes ${ }^{2}$ & .240 & $-13,247$ & -0.05 & 0.006 \\
\hline 10 & Science Attitudes * 21st Century Skills Attitudes & .243 & $-13,282$ & 0.06 & 0.009 \\
\hline
\end{tabular}

Note: Gender uses 'Female' as the reference level. All $p$-values are $<.0001$

\section{Multiple Linear Regression}

\section{Assumptions}

All statistical assumptions are met for multiple linear regression. For both regression models, residual plots show a linear trend, independence of residuals, and homoscedasticity. The QQ plots indicate that approximate normality holds. Bivariate correlations of all centered independent continuous variables used in either regression model show no indication of multicollinearity, with the highest correlation being .37 between Grade and Gradesquared, the quadratic term for Grade (Tabachnick \& Fidell, 2001, p. 82).

\section{CoreSTEM regression model}

The CoreSTEM model has an adjusted $\mathrm{R}^{2}$ of .437 . The parameter estimates can be seen in Table 6 . Science, Mathematics and Engineering/Technology attitudes are all positively related to CoreSTEM, with Engineering/Technology being the strongest effect and Science second. The positive interaction term indicates that higher Science attitudes means a stronger effect of Engineering/Technology attitudes on CoreSTEM interest. However, on average we see a slight decrease in CoreSTEM interest as 21st Century Skill attitudes increases. Also a number of demographic variables have unique contributions to the model. First, Male interest is higher than Female interest. In addition, underrepresented groups have a higher interest than overrepresented groups. Interpretation based on the size and sign of the Grade parameter estimates, CoreSTEM interest decreases with age, but it levels off at older grades.

\section{Bio/Med regression model}

The Bio/Med model with 10 effects had an adjusted $\mathrm{R}^{2}$ of .240. The parameter estimates can be seen in Table 7 . Both Science and Engineering/Technology attitudes are positively correlated with Bio/Med interest, as they were with CoreSTEM. Science has the largest effect in this model and is also an important variable in the CoreSTEM model. In a reverse of the CoreSTEM model, male interest is lower than female interest in Bio/Med careers. As with the CoreSTEM model, Bio/Med interest decreases as grade increases, then levels off in older grades. However, 
there are additional grade interaction terms with Science and Engineering/Technology terms that work in opposite directions. As grade increases, the association between Science attitudes on Bio/Med interest increases while the association between Engineering/Technology attitudes on Bio/Med interest decreases. Rather than the interaction of Science and Engineering/Technology attitudes seen in the CoreSTEM model, the Bio/Med model shows that higher 21st Century Skills attitudes is associated with a stronger effect of Science attitudes in the Bio/Med model. Both Race and STEM Adults were important in the CoreSTEM model but do not appear in the final Bio/Med model.

Notably, Mathematics attitudes was not selected as a predictor of Bio/Med career cluster interest. In fact, when we examined the full sequence of variables using no stopping criteria, mathematics attitudes did not enter the Bio/Med model until the 45th step. Additional analysis showed that forcing Mathematics attitudes into the model offered no improvement in model fit.

\section{DISCUSSION}

Our analysis provides important complimentary analysis to the body of research concerning STEM career pathways for elementary and secondary school children. In that regard, this work provides useful contrasts in terms of sample population and methodological approach while still utilizing common educational policy-driven motivations and underlying psychological models. By taking our approach, we provide, broadly speaking, triangulating evidence on key factors influencing STEM career pathways for young students.

An important distinction of our study relative to other work was the ability to collect data across all STEM academic and career areas. In doing so, we were able to examine student responses across science, mathematics, engineering/technology, and related STEM practices with a contemporary sample of students who have been exposed to recent educational trends, including increased emphasis on engineering practices in K-12 education. In doing so, we can compare prior findings regarding the relationship of the psychological constructs found in expectancy-value theory (Eccles \& Wigfield, 2002) and singular STEM disciplinary areas (e.g., mathematics) to our findings across all STEM areas.

Concerning the first research question, How do STEM career paths cluster based on student interest?, our findings reinforce prior research that students across key demographic factors perceive biological and physical science career paths differently (cf., Drechel et al., 2011; Riegle-Crumb \& King, 2010; Sadler et al., 2012), while also expanding the taxonomic reach of the findings. In addition to looking across physical and biological sciences, clinical professions with a biological basis (i.e., medical and veterinary fields) were shown to cluster as part of the Bio/Med cluster. Similarly, inclusion of mathematics and engineering allows us to see how these career areas clustered relative to science fields. Applying our own interpretive lens to the cluster findings, career areas that focused on living things largely separated themselves from these dealing with the inanimate. While certainly many finer distinctions could be made within fields such as Environmental Work or Earth Science that contradict this classification, based on the broader brush reinforced by the career definitions we provided, this largely holds true. Perhaps troubling in this conclusion is that areas such as engineering, in fact, have highly varied career opportunities, many of which do directly impact animals and humans. For example, biomedical engineering is a particularly fast growing area of engineering. Finally, perhaps another important finding that reinforces the conclusion that students view these two clusters of career areas differently is that the stepwise selection revealed important differences in terms of which variables were significantly related to each cluster, and the relationship of these predictor variables to cluster scores in the regression.

Addressing the second research question, What is the relationship between attitudes (self-efficacy and goal expectancy) in STEM academic areas to STEM career interests?, we first look at overarching findings and then focus on the subquestions. Stepwise selection using the BIC criterion proved to be a productive approach, though a cut-off of independent variables analyzed had to be applied to focus the analysis. The emergence of two career clusters resulted in important findings regarding the distinction between which variables were selected for each multiple regression model - both in regards to which were common, and those that were not, across clusters - and the results of the parameter estimates.

Addressing the overall question, What is the relationship between STEM academic attitudes and STEM career interest?, for those academic areas included in the two models, all the relationships between attitude, represented by constructs from expectancy-value theory, and career expectations were positive. Perhaps the most important finding is the place of mathematics attitudes relative to the other STEM areas. Both Engineering/Technology and Science appeared in the top five selected for both clusters, while Mathematics only appeared lower in the CoreSTEM model and was absent from the Bio/Med model based on our stepwise selection method. This finding is supported by Tai and colleagues (2006), who came to a similar conclusion as to the lack of a significant relationship of mathematics achievement and pursuing a biological sciences career path. It is also supported by Yerdelen and colleagues (2016), who found a positive relationship between mathematics attitudes and CoreSTEM career areas for Turkish middle grades students. For education experts with knowledge of mathematics' critical 
value across all STEM career areas, it is perhaps disconcerting that there seems to be disconnect between mathematics self-efficacy and outcome expectancy beliefs and interest in Bio/Med career areas, many of which require strong mathematics abilities. Our investigation of the mathematics variable with the Bio/Med model revealed that including mathematics attitudes offers no improvement in the fit of the model. Another interesting finding across both models was the fact that short-term performance perceptions of STEM coursework in science and mathematics did not figure prominently in the models. This is a finding that will need more theorizing and data collection to guide further conclusions.

The question, How do demographic variables of age, gender, and race/ethnicity relate to STEM career interest?, provided equally interesting findings, with each demographic factor deserving its own analysis. Grade as a primary and quadratic term was present in both models, supportive of the general conclusion that students' attitudes towards STEM careers are not static over their primary and secondary schooling (cf., Beal \& Crockett, 2010; Mau, 2003). However, the regression models show that while interest for both clusters decreases with age, it levels off for highschool-aged students. This leveling, or stabilizing, corresponds with prior research looking across high school grades with regards to future STEM career interests (Sadler et al., 2012). As noted by researchers, the causes behind this trend are likely complex and the result of numerous internal and external factors. We surmise that both a growing maturity of understanding of STEM careers coupled with a richer understanding of their own abilities and interests tightens students' focus around particular career trajectories, both within and outside of the STEM domain.

This self-selection process is seen in other demographic factors. Gender showed significantly different interest levels for the two clusters: males higher for CoreSTEM and females higher for Bio/Med. The presence of gender in both of the models was supportive of prior research using expectancy-value models (e.g., Simpkins et al., 2006; Watt et al., 2012) that has found broad support that males and females perceive STEM academic and career areas differently. This finding parallels a larger body of literature (e.g., Caleon \& Subramaniam, 2008; Miller et al., 2006; Osborne et al., 2003; Sadler et al., 2012; Watt et al., 2012) that has concluded boys and girls have differing attitudes towards STEM academic and career areas, and that girls generally favored the biological sciences while the reverse was true for physical sciences. As noted previously, we have added to this literature by being able to associate clinical sciences with the biological sciences, and engineering with physical sciences. However, it is interesting to note that the lack of interaction with age seems to diverge from findings in older studies (cf., Andre, Whigham, Hendrickson, \& Chambers, 1999; Greenfield, 1997) that found age and gender may interact in such a way as to cause a shift in gender differences as students get older.

Important differences were seen in the two regression models with regards to race/ethnicity. In looking at differences in career interest based on race and ethnicity, it is important to remember that our population was divided into over- and underrepresented populations (Beede, 2011) based on analysis of the current workforce, with African-Americans and Hispanics making up a large majority of the underrepresented population and Caucasians the majority of the overrepresented group. In the CoreSTEM model, race/ethnicity was selected and showed that underrepresented groups had a stronger interest in CoreSTEM careers than the overrepresented group, when all other variables were taken into account. In contrast, race/ethnicity was not selected for the Bio/Med model. This finding parallels findings by Riegle-Crumb and King (2010) that this racial/ethnic disparity in STEM career interests can be seen more readily in physical sciences and engineering than in the biological sciences, though perhaps not in the direction that would be expected based on actual workforce demographics. It is perhaps the broad sampling of students of all abilities that causes our findings to diverge from other studies, and calls for closer scrutiny of the experience of underrepresented populations as career directions are formalized. Byars-Winston et al. (2010) found a differing relationship between self-efficacy and career goals between biological science and engineering undergraduate majors from underrepresented groups. However, where their work found the significant relationship between biological science majors and self-efficacy, our findings found this relationship based on race/ethnicity in the CoreSTEM (including Engineering) model. This may point to a different set of contextual factors at work at younger ages. It is worth pointing out that knowing adults that worked in STEM fields was also only a significant factor in the CoreSTEM model.

These demographic variable findings diverge with some prior research. Maltese and Tai (2011) found no effect of gender and race on personal goals while Andersen and Ward (2013) found no significant relationship of gender and subjective task values. Given that both these longitudinal studies used high-achieving college-bound sample, differences in their samples and ours may be an important part of the explanation for the differences.

Addressing the question, How do attitudes towards 21st century skills relate to STEM career interest?, we start by noting that 21st century skills was selected for both regression models. However, this factor was negative in the CoreSTEM model while having an interactive relationship in the Bio/Med model. A negative relationship in the CoreSTEM model perhaps contradicts the popular association of these practices with physical sciences (including engineering). In the Bio/Med model, 21st century skill attitudes interacts with science attitudes, the strongest predictor in the model, such that increasing 21st century skill attitudes strengthens the positive relationship between science attitudes and Bio/Med career interests. Lack of deep prior literature makes it difficult to assess the 
implications of these findings regarding 21st century skill attitudes. However, these findings point to the fact that student attitudes towards these science and engineering practices have a significant relationship to STEM careers that differs based on career area.

There are a number of important implications for supporting students along STEM career trajectories. First and foremost, our work reinforces findings that students, as young as elementary grades, are forming attitudinal associations between their academic and life experience and future STEM career options. These associations are not monolithic, with STEM career interests dividing into two main groups with attitudinal relationships unique to each grouping. Our findings, supported by prior literature, demonstrate that boys and girls, and members of underrepresented populations, bring their own unique lenses to their relationship to STEM career areas. These differences need to be respected and addressed if the future STEM workforce, across all areas, is going to be representative of our population. There is concern that there is a demonstrated disconnect between mathematics and key STEM areas represented by the Bio/Med cluster. It perhaps points to the need for more and better modeling of how mathematics relates to both other STEM academic areas and future STEM career trajectories, especially those related to the Bio/Med cluster. Similarly, findings related to 21st century skills highlights the need to explore the relationship of students' actual school experiences with different STEM academic areas and how it shapes their perceptions of STEM career areas. It could be that the actual modeling of these practices (or the lack thereof) in K12 classes is a negative rather than positive factor in shaping attitudes. These challenges have particular importance in the middle grades, where stronger attitudinal shifts away from STEM careers seem to be taking place.

A number of limitations must be addressed for in order to best draw conclusions and address future areas of research. Regarding the sample, unlike many of the longitudinal studies utilizing national educational databases, our study utilized a cross-sectional sample of North Carolina public school students that are involved in schoolbased STEM education initiatives, though most of these initiatives were in their first year at the time of this survey. Although we do not have a reason to believe that North Carolina students differ than the rest of the nation in regards to their STEM attitudes and interest, it is possible. Our sample also differs somewhat in terms of racial/ethnic distribution from both current state and national statistics. Students in our sample may have been in STEM-focused schools, but this focus was not a specific treatment, nor was it analyzed for degree or consistency of exposure. However, these students are likely to have higher-than-average exposure to STEM career pathway options. Future research might aim to compare students in STEM-focused schools with those from the general population. Further, due to the nature of the initiative grants involved, our sample does not perfectly mirror the distribution of age for North Carolina public school students; in particular, high school students are slightly underrepresented. Further, our survey did not directly measure socioeconomic status, academic proficiency, or parental influence, all of which previous literature has shown may have an affect on student interest in pursuing STEM careers. Our hope is that future work will be able to link attitudes and career interest to these other factors to create a more comprehensive view of effects. For example, the adjusted $\mathrm{R}^{2}$ value of .24 for the Bio/Med model indicates that, although much variance is explained by the independent variables, other unmeasured variables also contribute to the explanation of Bio/Med career interest. Another enlightening area of future research would be to explore student attitudes toward non-STEM careers instead of solely STEM careers. This would give a more complete picture of K-12 student career interest, giving insight into whether or not the trends we saw were unique to STEM, such as the overall decline in STEM career interest for older students. Another research goal is to link SSTEM survey data with future decisions about attending college and selecting a college major, all leading to a more complete picture of how student attitudes, starting even in elementary school, can lead to certain college outcomes and STEM careers.

\section{ACKNOWLEDGEMENTS}

Portions of this material are based upon work supported by the National Science Foundation under Grant DUE1038154. Portions of the work were also supported by the Golden LEAF Foundation.

\section{REFERENCES}

ACT. (2009). Act Interest Inventory Technical Manual. Retrieved from Iowa City, IA: http:/ / www.act.org/stemcondition/14/pdf/National-STEM-Report-2014.pdf

ACT. (2014). The Condition of STEM 2014. Retrieved from http://www.act.org/stemcondition/14/pdf/NationalSTEM-Report-2014.pdf

Andersen, L., \& Ward, T. J. (2013). Expectancy-Value Models for the STEM Persistence Plans of Ninth-Grade, HighAbility Students: A Comparison between Black, Hispanic, and White Students. Science Education, 98(2), 216242. https:// doi.org/10.1002/sce.21092 
Andre, T., Whigham, M., Hendrickson, A., \& Chambers, S. (1999). Competency beliefs, positive affect, and gender stereotypes of elementary students and their parents about science versus other school subjects. Journal of Research in Science Teaching, 36(6), 719-747. https:/ / doi.org/10.1002/(SICI)1098-2736(199908)36:6<719::AIDTEA8>3.0.CO;2-R

Beal, S. J., \& Crockett, L. J. (2010). Adolescents' occupational and educational aspirations and expectations: Links to high school activities and adult educational attainment. Developmental Psychology, 46(1), 258-265. https:/ / doi.org/10.1037/a0017416

Beede, D., Julian, T., Khan, B., Lehrman, R., McKittrick, G., Langdon, D., \& Doms, M. (2011). Education Supports Racial and Ethnic Equality in STEM. ESA Issue Brief\# 05-11 (05-11).

Brotman, J. S., \& Moore, F. M. (2008). Girls and science: A review of four themes in the science education literature. Journal of Research in Science Teaching, 45(9), 971-1002. https:/ / doi.org/10.1002/ tea.20241

Byars-Winston, A., Estrada, Y., Howard, C., Davis, D., \& Zalapa, J. (2010). Influence of social cognitive and ethnic variables on academic goals of underrepresented students in science and engineering: a multiple-groups analysis. Journal of Counseling Psychology, 57(2), 205. https:/ / doi.org/10.1037/a0018608

Caleon, I. S., \& Subramaniam, R. (2008). Attitudes towards science of intellectually gifted and mainstream upper primary students in Singapore. Journal of Research in Science Teaching, 45(8), 940-954.

Chen, P., \& Zimmerman, B. (2007). A Cross-National Comparison Study on the Accuracy of Self-Efficacy Beliefs of Middle-School Mathematics Students. The Journal of Experimental Education, 75(3), 221 - 244.

Chen, X. (2009). Students Who Study Science, Technology, Engineering, and Mathematics (STEM) in Postsecondary Education. Retrieved from http://nces.ed.gov/pubs2009/2009161.pdf

Cisco Systems. (2008). Equipping every learner for the 21st century. White paper. San Jose, CA: Author

Correl, S. (2001). Gender and the career choice process: The role of biased self-assessments. American Journal of Sociology, 106(6), 1691-1730.

Deci, E. L., \& Ryan, R. M. (1985). Intrinsic motivation and self-determination in human behavior. New York: Plenum.

DeWitt, J., Archer, L., \& Osborne, J. (2014). Science-related Aspirations across the Primary-Secondary Divide: Evidence from two surveys in England. International Journal of Science Education, 36(10), 1609-1629. https:/ / doi.org/10.1080/09500693.2013.871659

DeWitt, J., Osborne, J., Archer, L., Dillon, J., Willis, B., \& Wong, B. (2011). Young children's aspiration in science: The unequivocal, the uncertain and the unthinkable. International Journal of Science Education, 35(6), 10371063. https:/ / doi.org/10.1080/09500693.2011.608197

Douglas, K., Rynearson, A., Yoon, S., \& Diefes-Dux, H. (2015). Two elementary schools' developing potential for sustainability of engineering education. International Journal of Technology and Design Education, 1-26. https:// doi.org/10.1007/s10798-015-9313-4

Drechsel, B., Carstensen, C., \& Prenzel, M. (2011). The Role of Content and Context in PISA Interest Scales: A study of the embedded interest items in the PISA 2006 science assessment. International Journal of Science Education, 33(1), 73-95. https:/ / doi.org/10.1080/09500693.2010.518646

Eccles, J. S. (1994). Understanding Women's Educational and Occupational Choices: Applying the Eccles et al. Model of Achievement-Related Choices. Psychology of Women Quarterly, 18(4), 585-609. https:/ / doi.org/10.1111/j.1471-6402.1994.tb01049.x

Eccles, J. S., \& Wigfield, A. (2002). Motivational beliefs, values, and goals. Annual Review of Psychology, 53, 109-132.

Eccles, J. S., Vida, M. N., \& Barber, B. (2004). The relation of early adolescents' college plans and both academic ability and task-value beliefs to subsequent college enrollment. The Journal of Early Adolescence, 24(1), 63-77.

Fouad, N. A., \& Smith, P. L. (1996). A test of a social cognitive model for middle school students: Math and science. Journal of Counseling Psychology, 43(3), 338-346. https:/ / doi.org/10.1037/0022-0167.43.3.338

Ginder, S., \& Mason, M. (2011). Postsecondary Awards in Science, Technology, Engineering, and Mathematics (STEM), by State: 2001 and 2009 (Report \# NCES 2011-226). Retrieved from http:/ / nces.ed.gov/pubs2011/2011226.pdf

Greenfield, T. A. (1997). Gender- and grade-level differences in science interest and participation. Science Education, 81(3), 259-276. https:/ / doi.org/10.1002/(SICI)1098-237X(199706)81:3<259::AID-SCE1>3.0.CO;2-C

Guo, J., Marsh, H. W., Morin, A. J. S., Parker, P. D., \& Kaur, G. (2015). Directionality of the Associations of High School Expectancy-Value, Aspirations, and Attainment: A Longitudinal Study. American Educational Research Journal. https:/ / doi.org/10.3102/0002831214565786 
Hazari, Z., Sonnert, G., Sadler, P. M., \& Shanahan, M. C. (2010). Connecting High School Physics Experiences, Outcome Expectations, Physics Identity, and Physics Career Choice: A Gender Study. Journal of Research in Science Teaching, 47(8), 978-1003. https:/ / doi.org/10.1002/tea.20363

ITEEA, International Technology and Engineering Educators Association. (2018). Homepage. Retrieved from http:/ / www.iteea.org

Jaccard, J., \& Turrisi, R. (Eds.). (2003). Interaction Effects in Multiple Regression (2nd ed.). Thousand Oaks, CA: SAGE Publications, Inc. https:/ / doi.org/10.4135/9781412984522

James, G., Witten, D., Hastie, T., \& Tibshirani, R. (2013). An Introduction to Statistical Learning. New York: Springer.

Jenkins, E. W., \& Nelson, N. W. (2005). Important but not for me: students' attitudes towards secondary school science in England. Research in Science $\mathcal{E}$ Technological Education, 23(1), 41-57. https:/ / doi.org/10.1080/02635140500068435

Katehi, L., Pearson, G., \& Feder, M. (2009). Engineering in K-12 Education: Understanding the Status and Improving the Prospects (ISBN 978-0-309-13778-2). Retrieved from http:/ / www.nap.edu/catalog.php?record_id=12635

Maltese, A. V., \& Tai, R. H. (2011). Pipeline persistence: Examining the association of educational experiences with earned degrees in STEM among U.S. students. Science Education, 95(5), 877-907. https:// doi.org/10.1002/sce.20441

Mau, W.-C. (2003). Factors That Influence Persistence in Science and Engineering Career Aspirations. Career Development Quarterly, 51(3), 234-243.

Miller, C. C. (2014). Google Releases Employee Data, Illustrating Tech's Diversity Challenge, New York Times. Retrieved from http:/ / nyti.ms/1heUoxU5/14

Miller, P. H., Slawinski Blessing, J., \& Schwartz, S. (2006). Gender differences in high school students' views about science. International Journal of Science Education, 28(4), 363-381.

NAE, National Academy of Engineering. (2014). STEM Integration in K-12 Education: Status, Prospects, and an Agenda for Research. Washington, DC: National Academies Press.

NAEP, National Assessment of Educational Progress. (2014). Technology and Engineering Literacy Student Questionnaire (TELSQ) 2014 Grade 8 Computer-based Assessment. Washington, DC: NAEP.

Nathan, M., Oliver, K., Prevost, A., Tran, N., \& Phelps, A. (2009). Classroom Learning and Instruction in High School Pre-College Engineering Settings: A Video-Based Analysis. Paper presented at the American Society for Engineering Education, Austin, TX.

NCDPI, North Carolina Department of Public Instruction. (2009). North Carolina Public Schools Statistical Profile. Raleigh, NC.

NCSES, National Center for Science and Engineering Statistics. (2013). Science and Engineering Degrees: 1966 - 2010 (13-327). Retrieved from http:/ / www.nsf.gov/statistics/nsf13327/

NGSS Lead States. (2013). Next Generation Science Standards. Washington, DC: The National Academies Press.

NRC, National Research Council. (2010). Rising above the gathering storm, revisited: Rapidly rising to category 5. Washington, DC: Author

NSF, National Science Foundation. (2009). Women, minorities, and persons with disabilities in science and engineering: 2009 (NSF 09 - 305). Arlington, VA: Author

OECD, Organisation for Economic Co-operation and Development. (2006). PISA assessing scientific, reading and mathematical literacy: A framework for PISA 2006. Paris: Author

Osborne, J., Simon, S., \& Collins, S. (2003). Attitudes towards science: A review of the literature and its implications. International Journal of Science Education, 25(9), 1049-1079.

Pajares, F., \& Graham, L. (1999). Self-Efficacy, Motivation Constructs, and Mathematics Performance of Entering Middle School Students. Contemporary Educational Psychology, 24(2), 124-139. https:/ / doi.org/10.1006/ceps.1998.0991

PCAST, President's Council of Advisors on Science and Technology. (2010). Prepare and Inspire: K-12 Education in Science, Technology, Engineering, and Math (STEM) for America's Future. Washington, DC: Executive Office of the President

PCAST, President's Council of Advisors on Science and Technology. (2012). Engage to excel: Producing one million additional college graduates with degrees in science, technology, engineering and mathematics. Washington, DC: Executive Office of the President

PTCS, Partnership for 21st Century Skills. (2005). Learning for the 21st Century. Retrieved from http://www.21stcenturyskills.org/images/stories/otherdocs/P21_Report.pdf 
Riegle-Crumb, C., \& King, B. (2010). Questioning a White Male Advantage in STEM Examining Disparities in College Major by Gender and Race/Ethnicity. Educational Researcher, 39(9), 656-664. https:/ / doi.org/10.3102/0013189X10391657

Rothwell, J. (2013). The Hidden STEM Economy. The Metropolitan Policy Program at Brookings: Washington, DC.

Sadler, P. M., Sonnert, G., Hazari, Z., \& Tai, R. (2012). Stability and volatility of STEM career interest in high school: A gender study. Science Education, 96(3), 411-427. https:/ / doi.org/10.1002/sce.21007

SAS Institute Inc. (2014). SAS/STAT® 13.2 User's Guide. Cary, NC: Author.

Schunk, D. H. (1991). Self-Efficacy and Academic Motivation. Educational Psychologist, 26, 207-232.

Schwarz, G. (1978). Estimating the Dimension of a Model. The Annals of Statistics, 6(2), 461-464.

Scott, A. B., \& Mallinckrodt, B. (2005). Parental Emotional Support, Science Self-Efficacy, and Choice of Science Major in Undergraduate Women. Career Development Quarterly, 53(3), 263-273.

Simon, R. A., Aulls, M. W., Dedic, H., Hubbard, K., \& Hall, N. C. (2014). Exploring Student Persistence in STEM Programs: A Motivational Model. Canadian Journal of Education, 38(1), 1-27.

Simpkins, S. D., Davis-Kean, P. E., \& Eccles, J. S. (2006). Math and science motivation: A longitudinal examination of the links between choices and beliefs. Developmental Psychology, 42(1), 70.

Tabachnick, B. G., \& Fidell, L. S. (2001). Using multivariate statistics (4th ed.). Allyn and Bacon. https:// doi.org/10.1037/022267

Tai, R. H., Qi Liu, C., Maltese, A. V., \& Fan, X. (2006). Planning Early for Careers in Science. Science, 312(5777), 11431144. https:// doi.org/10.1126/science.1128690

Truxillo, C. (2005). Maximum Likelihood Parameter Estimation with Incomplete Data. In Proceedings of the Thirtieth Annual SAS® Users Group International Conference (paper 111-30). Cary, NC: SAS Institute Inc.

U.S. Bureau of Labor Statistics (2011). Occupational Outlook Handbook. Retrieved on May, 2017 from https://www.bls.gov/ooh/

Unfried, A., Faber, M., \& Wiebe, E. (2014). Gender and Student Attitudes toward STEM. Presented at the AERA Annual Meeting, Philadelphia, PA.

Unfried, A., Faber, M., Stanhope, D. \& Wiebe, E. (2015). The development and validation of a measure of student attitudes toward science, technology, mathematics, and engineering. Journal of Psychoeducational Assessment 33(7), 622-639. https:/ / doi.org/10.1177/0734282915571160

USCB, U.S. Census Bureau. (2016). ACS Demographic and Housing Estimates, 2016. Retrieved on March, 2018 from https:/ / factfinder.census.gov/faces/tableservices/jsf/pages/productview.xhtml?pid=ACS_16_5YR_DP0 $5 \& \mathrm{src}=\mathrm{pt}$

Wang, M.-T. (2012). Educational and career interests in math: A longitudinal examination of the links between classroom environment, motivational beliefs, and interests. Developmental Psychology, 48(6), 1643-1657. https:/ / doi.org/10.1037/a0027247

Washington, J. (2011). What's behind declining numbers of blacks in science, tech, engineering and math fields? AP.

Watson, M., \& McMahon, M. (2005). Children's career development: A research review from a learning perspective. Journal of Vocational Behavior, 67(2), 119-132. https:/ / doi.org/10.1016/j.jvb.2004.08.011

Watt, H. M. G., Shapka, J. D., Morris, Z. A., Durik, A. M., Keating, D. P., \& Eccles, J. S. (2012). Gendered motivational processes affecting high school mathematics participation, educational aspirations, and career plans: A comparison of samples from Australia, Canada, and the United States. Developmental Psychology, 48(6), 15941611. https:// doi.org/10.1037/a0027838

Wigfield, A., \& Eccles, J. S. (2000). Expectancy-value theory of achievement motivation. Contemporary Educational Psychology, 25(1), 68-81.

Xie, Y., \& Achen, A. (2009). Science on the decline? Educational outcomes of three cohorts of young Americans. Ann Arbor, MI: Population Studies Center, University of Michigan

Yerdelen, S., Kahraman, N., \& Tas, Y. (2016). Low Socioeconomic Status Students' STEM Career Interest in Relation to Gender, Grade Level, and STEM Attitude. Journal of Turkish Science Education, 13, 59-74.

Yerdelen-Damar, S., \& Pesman, H. (2013). Relations of Gender and Socioeconomic Status to Physics through Metacognition and Self-Efficacy. Journal of Educational Research, 106(4), 280-289. https:/ / doi.org/10.1080/00220671.2012.692729 
Yildirim, B., \& Selvi, M. (2015). Adaption of STEM Attitude Scale to Turkish. Electronic Turkish Studies, 10(3), 11171130.

Yore, L., Bisanz, G. L., \& Hand, B. M. (2003). Examining the literacy component of science literacy: 25 years of language arts and science research. International Journal of Science Education, 25(6), 689-725.

\section{http://www.ejmste.com}

